\title{
Genetic Testing in Amyloidosis: For Whom?
}

\author{
Paulo Vinicius Ramos Souza, ${ }^{1,2}$ Fabio Fernandes, ${ }^{1}$ Felix José Alvarez Ramires ${ }^{1} \bullet$ \\ Unidade Clínica de Miocardiopatias e Doenças da Aorta do Instituto do Coração do Hospital das Clínicas da Faculdade de Medicina da \\ Universidade de São Paulo - InCor HC FMUSP,1 São Paulo, SP - Brazil \\ Universidade Metropolitana de Santos - UNIMES, ${ }^{2}$ Santos, SP - Brazil
}

Over the past years, the recognition of cardiac involvement due to deposition of amyloid substances has received greater emphasis. Cardiac amyloidosis (CA), as it is known, has been shown to be a more prevalent cause of heart failure with preserved ejection fraction than in previous decades, although diagnosis remains a constant challenge.

With advances in pathophysiological knowledge of this disease, as well as relevant advances in diagnostic methods, particularly in the field of cardiovascular imaging, there has been a significant contribution to earlier identification of CA, as well as a consistent change in the natural course of the disease, given that we are witnessing the emergence of therapies that are capable of prolonging these patients' survival.

As part of this diagnostic evolution, we have also witnessed an expressive increase in knowledge in the genetic field, which has become a powerful tool in the clinical arsenal for diagnosis of CA. To better understand the role of genetic testing in CA, it is worth detailing the main forms of cardiac alterations in amyloidosis.

Among the forms of amyloidosis that may affect the heart, the following 5 different types of amyloidogenic proteins stand out: heavy and light immunoglobulin chains, transthyretin (TTR), amyloid A, and apo A1. Two of these are responsible for about 95\% of cases of AC: immunoglobulin light chain deposits (AL form) and transthyretin (ATTR form). ${ }^{1-3}$

In the AL form, amyloid light chain proteins originate from plasma cells or from anomalous B lymphocytes, configuring a clonal or neoplastic hematological disease. ${ }^{4}$

Another typical presentation of AC occurs through accumulation and deposition of an amyloid protein called TTR. TTR is a protein composed of four monomers, which circulate as a tetramer ${ }^{5}$ and which, under physiological conditions, function as a transporter of thyroxine (T4) and retinol (vitamin E). The limiting step in the rate of amyloid fibril formation by TTR is the dissociation of the tetramer into monomers, which possibly involves proteolysis. Subsequently, the partial denaturation of the monomer can lead to incorrect assembly of this protein in various aggregate structures. ${ }^{6}$

\section{Keywords}

Amyloidosis; Genetic Testing; Prealbumin.

Mailing Address: Felix José Alvarez Ramires •

Av. Dr. Enéas de Carvalho Aguiar, 44, AB-C6. Postal Code 05403-000,

São Paulo, SP - Brazil

E-mail: felix.ramires@incor.usp.br

Manuscript received September 16, 2021, revised manuscript September 26, 2021, accepted September 26, 2021.

DOI: https://doi.org/10.36660/abchf.20210025
When this inappropriate assembly is caused by a mutation in the TTR gene, changing the amino acid sequence, it is known as variant or hereditary TTR amyloidosis (ATTRv). This mutation has an autosomal dominant character; its gene is located on chromosome 18, and several types of mutations have been described. ${ }^{7}$

Furthermore, there also exists an acquired form of TTR accumulation, known as the wild type, where the amino acid sequence is normal. The process through which this wild protein becomes unstable and aggregates into amyloid fibrils, causing wild-type TTR amyloidosis (ATTRwt) is not entirely clear. ${ }^{7}$

It is precisely in this scenario of differentiating between ATTRv (the hereditary form) and ATTRwt (the acquired form) that diagnostic genetic testing becomes strongest and is most highly indicated. In accordance with the "Position Statement on Diagnosis and Treatment of Cardiac Amyloidosis" ${ }^{6}$ of the Brazilian Society of Cardiology, it has been given a class I recommendation with level of evidence $B$, based on the findings of the Spanish study that estimated the prevalence of allelic variants in the TTR gene through analysis of large-scale sequencing data. ${ }^{8}$

Among genetic aspects, another important point that has been increasingly underscored is the screening of presymptomatic patients. This category includes relatives of people who are known to be affected by the inherited form of ATTRv.

Unlike genetic diagnostic testing, screening of pre-symptomatic patients should only be conducted if patient expressly state that this is their will and if they are considered psychologically prepared. For this purpose, the test must be conducted by trained professionals, and there must be a psychological support team. In addition to the mandatory inclusion of a pre-diagnostic preparation phase, in this scenario, genetic testing must also provide a post-result support phase. ${ }^{9}$

Given that all forms of hereditary amyloidosis begin in adulthood, genetic testing of minors is discouraged. Genetic testing may be offered during young adulthood if the genetic information would be useful to guiding career choices or reproductive planning. As age at onset, penetrance, and disease progression depend on the genetic variant, assessment of penetrance in carriers of the allele is generally recommended starting 10 years before the age of disease onset in affected family members (or other individuals with the same mutation), or as soon as symptoms that are compatible with amyloidosis develop. ${ }^{10}$

In addition to the aforementioned recommendations, genetic testing allows us to infer some correlations between mutations and possible phenotypes of amyloidosis involvement. More than 140 different types of mutations have been identified, and not all of them are pathological. ${ }^{11}$

Although the genotypic and phenotypic correlation is not strict, it is possible to mention some pathogenic 


\section{Viewpoint}

mutations with greater tendency toward neurological (TTRv V30Met) and cardiac (TTRv V122I) involvement, as well as some that occur with both neuropathy and heart disease (Leu58Hist). ${ }^{12}$

We therefore conclude that genetic testing in amyloidosis has a precise recommendation for distinguishing the hereditary TTR form (ATTRv) from the acquired TTR form (ATTRwt), as well as in screening of pre-symptomatic patients (relatives of people who are known to be affected by ATTRv), provided that they express this wish.

\section{Author contributions}

Writing of the manu; Critical revision of the manuscript for intellectual content; Supervision: Souza PVR, Ramires FJA, Fernandes F.

\section{References}

1. Falk RH, Alexander KM, Liao R, Dorbala S. AL (Light-Chain) Cardiac Amyloidosis: A Review of Diagnosis and Therapy. J Am Coll Cardiol. 2016;68(12):1323-41. doi: 10.1016/j.jacc.2016.06.053.

2. Ruberg FL, Berk JL. Transthyretin (TTR) Cardiac Amyloidosis. Circulation. 2012;126(10):1286-300. doi: 10.1161/CIRCULATIONAHA.111.078915.

3. Gertz MA, Dispenzieri A, Sher T. Pathophysiology and TREATMENT OF Cardiac Amyloidosis. Nat Rev Cardiol. 2015;12(2):91-102. doi: 10.1038/ nrcardio.2014.165.

4. Mankad AK, Sesay I, Shah KB. Light-Chain Cardiac Amyloidosis. Curr Probl Cancer. 2017;41(2):144-56. doi: 10.1016/j.currproblcancer.2016.11.004.

5. Koike H, Katsuno M. Ultrastructure in Transthyretin Amyloidosis: From Pathophysiology to Therapeutic Insights. Biomedicines. 2019;7(1):11. doi: 10.3390/biomedicines7010011.

6. Simões MV, Fernandes F, Marcondes-Braga FG, Scheinberg P, Correia EB, Rohde LEP, etal. Posicionamento sobre Diagnósticoe Tratamento daAmiloidoseCardíaca -2021. Arq. Bras. Cardiol. 2021;117(3):561-98. doi: 10.36660/abc.20210718.

7. Ruberg FL, Grogan M, Hanna M, Kelly JW, Maurer MS. Transthyretin Amyloid Cardiomyopathy: JACC State-of-the-Art Review. J Am Coll Cardiol. 2019;73(22):2872-91. doi: 10.1016/j.jacc.2019.04.003.

\section{Potential Conflict of Interest}

No potential conflict of interest relevant to this article was reported.

\section{Sources of Funding}

There were no external funding sources for this study.

\section{Study Association}

This study is not associated with any thesis or dissertation work.

\section{Ethics approval and consent to participate}

This article does not contain any studies with human participants or animals performed by any of the authors.

8. Pueyo CL, Arregui MÁA, Gutierrez AG, Juana EB, Guillén SM. Estimating the Prevalence of Allelic Variants in the Transthyretin Gene by Analysing Large-Scale Sequencing Data. Eur J Hum Genet. 2019;27(5):783-91. doi: 10.1038/s41431-019-0337-1.

9. Obici L, Kuks JB, Buades J, Adams D, Suhr OB, Coelho T, et al, Recommendations for Presymptomatic Genetic Testing and Management of Individuals at Risk for Hereditary Transthyretin Amyloidosis. Curr Opin Neurol. 2016;29(Suppl 1):27-35. doi: 10.1097/ WCO.0000000000000290.

10. Conceição I, Coelho T, Rapezzi C, Parman Y, Obici L, Galán L, et al Assessment of Patients with Hereditary Transthyretin Amyloidosis Understanding the Impact of Management and Disease Progression. Amyloid. 2019;26(3):103-11. doi: 10.1080/13506129.2019.1627312.

11. Park GY, Jamerlan A, Shim KH, An SSA. Diagnostic and Treatment Approaches Involving Transthyretin in Amyloidogenic Diseases. Int J Mol Sci. 2019;20(12):2982. doi: 10.3390/ijms20122982.

12. Maurer MS, Bokhari S, Damy T, Dorbala S, Drachman BM, Fontana M, et al. Expert Consensus Recommendations for the Suspicion and Diagnosis of Transthyretin Cardiac Amyloidosis. Circ Heart Fail. 2019;12(9):e006075. doi: 10.1161/CIRCHEARTFAILURE.119.006075. 